\title{
THE IMPACT OF GLOBALIZATION ON THE DIGITAL ECONOMY IN BULGARIA
}

\author{
Maria Kicheva ${ }^{1}$ \\ Nadezhda Petkova ${ }^{2}$ (D)
}

DOI: https://doi.org/10.31410/ITEMA.2019.229

\begin{abstract}
Globalization is the reason for significant changes in all spheres of life. Its effects on the world economy have been observed for a long time. The impact of globalization is an important economic matter and its research is as important.

The aim of this research is to track the trends in the development of the digital economy in Bulgaria and the corresponding occurring change which follow it. Bulgaria established itself as one of the key centers for innovative development in 2018 and one of the reasons for that is precisely the globalization in the sphere of economy and information and communications technologies. The country's digital economy forestalls the trends and grows 2.5 times faster than the economies of the big five on the European Union's market. The transformation of the Bulgarian economy would increase its competitiveness and would place it at a leading position in the region. Due to these and many other reasons it is important for these matters to be analyzed from a scientific point of view.

This paper contributes for the clearer formulation and understanding of the matters related to globalization as a whole, but also for tracking its impact on the state of digital companies in Bulgaria. Similar research can be applied and further developed for each and every European country and more.
\end{abstract}

Keywords: Globalization, Digital Economy, Bulgaria, Innovation.

\section{INTRODUCTION}

$\mathrm{T}$ he globalization of the world gives opportunities for a new, "global" demand, an exchange of new products and services and cultural enrichment to be created. Globalization is what eliminates market's boundaries by creating innovative opportunities for the entrepreneurial business. Globalization is an important factor for the worldwide economy's development. It is a phenomenon that leads to both prosperity and in the same time to problems in different spheres of society. "Globalization" is a term commonly used as a synonym for the increasing internationalization that supposes the shift of influence from national governments to transnational corporations. The process itself is connected to the distribution and interpenetration of ideas, capital, technology, and elements of culture. In the face of economic globalization, a new necessity might have emerged: a necessity for consideration and/or re-consideration, as well as one for an analysis of its impact on the economic and social development of separate regions and especially a necessity for an effective management of the factors that influence those processes. Globalization influences the regional distribution within the framework of every national economy differently. Having in mind the set of factors that constitute such global economic model, which includes newer and newer technologies, new markets, etc., the contribution of science on bringing forward non-technological innovations (marketing or organization related ones) will become more and more important. The role of the human factor, the approaches and the mechanisms for impacting people

1 South-West University „Neofit Rilski“, Faculty of Economics, Department of Economics, 66 Ivan Mihaylov Str., Blagoevgrad, Bulgaria

2 South-West University „Neofit Rilski“, Faculty of Economics, Department of Economics, 66 Ivan Mihaylov Str., Blagoevgrad, Bulgaria 
is more clearly defined due to the efforts of the scientific community. Accordingly, the result from the scientific contribution will be measured through using people as the most valuable asset and possible carrier of a continuing advanced competitive advantage for every economic entity.

One of the phenomena that occurred mostly due to the processes related to globalization in terms of technology is precisely the digital revolution for the last few decades. According to the Digital Economy Report (2019), "The digital economy continues to evolve at breakneck speed, driven by the ability to collect, use and analyse massive amounts of machine-readable information (digital data) about practically everything" (p.1). The report also notes that "The expansion of the digital economy creates many new economic opportunities. Digital data can be used for development purposes and for solving societal problems. It can thus help improve economic and social outcomes, and be a force for innovation and productivity growth. Platforms facilitate transactions and networking as well as information exchange. From a business perspective, the transformation of all sectors and markets through digitalization can foster the production of higher quality goods and services at reduced cost. Furthermore, digitalization is transforming value chains in different ways, and opening up new channels for value addition and broader structural change" (2019, Digital Economy Report, p.3-4).

\section{THE DIGITAL ECONOMY IN BULGARIA}

A number of companies and organizations create innovative solutions for this new era. This corresponds to the increase in users and consumers of the new generation of product and services. Every day, around 360 million Europeans work, study, shop, buy and sell online and this number keeps constantly growing. With the help of digital technologies, we see the improvement of systems of communication, education, health, transport, manufacturing, security, agriculture, as well as the definition of solutions to combat climate change. Many of these changes have appeared due to the processes of development and globalization in the field of technology. In Bulgaria, cutting-edge solutions are being developed by both startups and traditional businesses and their innovative teams. Those people are also the capital for developing the innovative economy of the country.

On the one hand, Bulgaria has very high chances of transforming its economy through digitalization. Thus, it will increase the country's competitiveness and it will become a leader in the region in this field. There are many ideas, projects and development opportunities already. An evidence of the country's potential is the fact that the digital economy in Bulgaria is growing significantly in comparison to the tendencies in Europe. The rate of increase is two and a half times faster than the one of the Big 5 on the market of the European Union (Germany, France, Italy, the United Kingdom and Spain) as we can see in Figure 1. of the paper.

The period between 2012 and 2016 has been a very successful one for the digital economy in Bulgaria as an increase of $8.2 \%$ has been reported while the one of the Big 5 on the market is $3.1 \%$. The country outnumbers the other countries in Central and Eastern Europe (CEE) as well where the increase is on average $6.2 \%$. However, it is still behind the digital pioneers - the most digitalized countries on the continent are the Northern nations. For example, Switzerland's digital economy growth is $9.9 \%$.

Traditional drivers of success are getting less and less significant. This is the reason why there is a focus on digitalization all over the world. According to McKinsey \& Company's analysis (2019), "Bulgaria can build on its strong digital economy growth to catch up with Digital Frontrunners" (p.4). Moreover, it is what can bring additional $€ 8$ billion of GDP until 2025. They are also predicting the amount for the whole region (CEE) to reach up to $€ 200$ billion. 


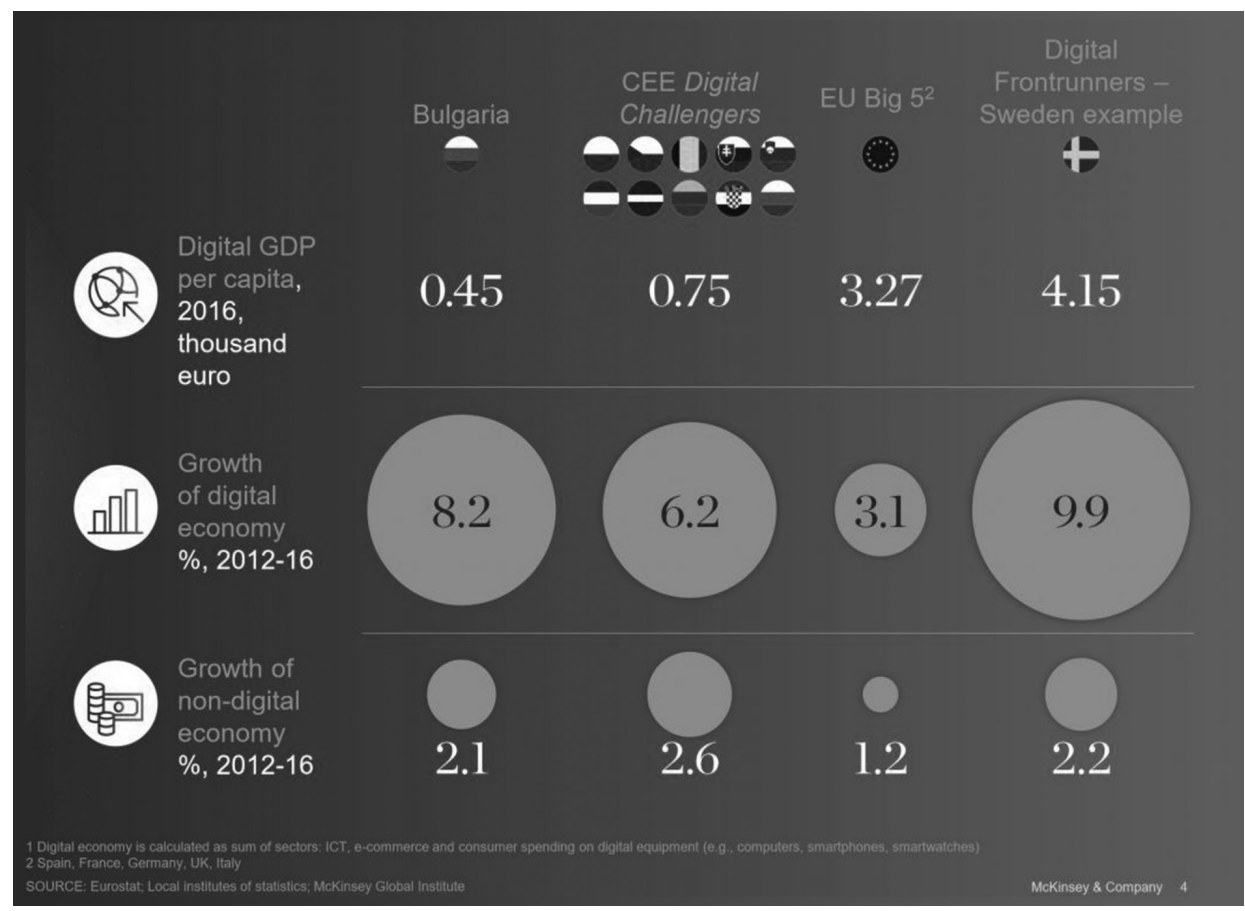

Figure 1. The potential of the Bulgarian digital economy.

Source: McKinsey \& Company, The Rise of the Digital Challenges: How digitalization can become the new growth engine for Bulgaria Central and Eastern Europe (2019)

Also, according to the IMD World Digital Competitiveness Ranking, which is a ranking of 63 countries from all over the world including some European Countries, Australia, Canada, Chile, USA, Saudi Arabia, Russia and more, Bulgaria ranks $45^{\text {th }}$ for 2019. If we look at the separate factors included in the report, we can see that the country has moved from $54^{\text {th }}$ place in 2015 to $45^{\text {th }}$ in 2019. In terms of the factor knowledge there is an upward movement for the last four years. As far as the factor technology is concerned, there is a steady result and when it comes to future readiness the country also shows a great improvement, moving from $59^{\text {th }}$ place in 2015 to $48^{\text {th }}$ place in 2019.

However, there are some challenges before the development of the digital economy in Bulgaria as pointed out in the report Innovation Ship Bulgaria Digital 2018. Some of them include: there is a shortage of qualified personnel which turns out to be a major difficulty for new or already established digital companies; heavy administrative procedures and lack of institutional support are also important barriers for the rapid expansion of the field.

On the other hand, if we compare Bulgaria to all state-members of the European Union in terms of DESI (Digital Economy and Society Index) for 2019 we see in Figure 2. that it ranks last. Despite the potential that the digital economy in Bulgaria has, as we have discussed in the paper before, its rank decreased due to two main reasons: a limited performance in some of the DESI dimensions measured and better performance of the other member states in some of the indicators included in the index. The indicators included in the index are connectivity, human capital, use of Internet services, integration of digital technology and digital public services.

All these factors are very important for the digitalization of the economy which in 21th century has the potential to bring great opportunities for growth, increased competitiveness and improved business environment in a country as a whole. 


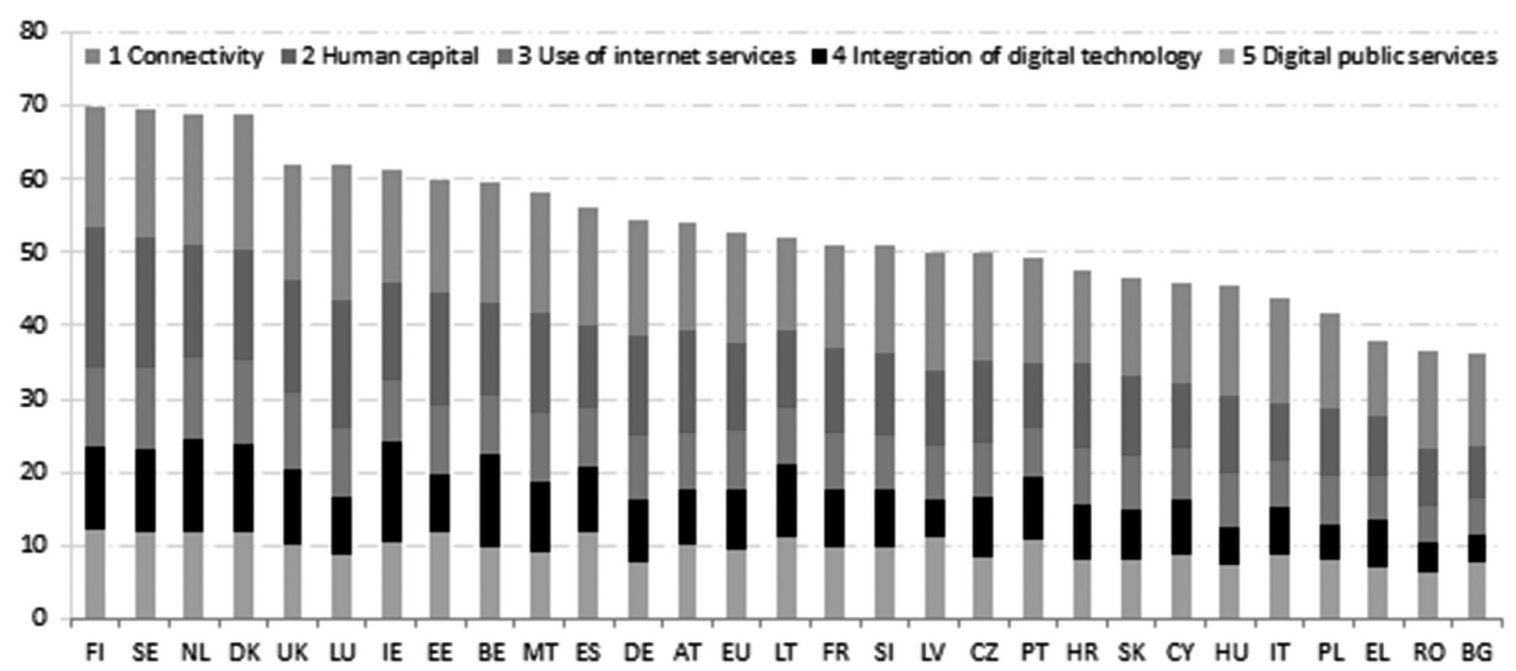

Figure 2. Digital Economy and Society Index (DESI) 2019 ranking

Source: European Commission, https://ec.europa.eu/digital-single-market/en/scoreboard/bulgaria

The results of the European Commission's report show that Bulgaria performs relatively well in connectivity, especially as regards to the wide availability of ultrafast and mobile broadband networks. It has also made significant progress with the e-government dimension, with growing number of users and a high score for the provision of digital public services to businesses. However, Bulgaria scores well below the average in human capital, its overall level of digital skills being among the EU's lowest. People with at least basic digital skills account for $29 \%$ of the total Bulgarian population, against an EU average of $57 \%$. Only $11 \%$ of people have skills that are above basic, which equals almost one third of the EU average. Bulgaria also performs well below the average in integrating digital technology. Companies are not yet taking full advantage of the possibilities offered by online commerce: $6 \%$ of SMEs sell online (against the $17 \%$ of the EU average), $3 \%$ of total SMEs are selling cross-border and an only $2 \%$ of their turnover comes from the online segment. Bulgaria has a National Programme linked to the programming of EU structural funds called „Digital Bulgaria 2025”, which outlines some measures to improve connectivity, public services and private sector integration of digital technologies. However, this is not an overarching strategy to support digital transformation in Bulgaria. A concept note for the Industry 4.0 strategy was elaborated in 2017 but it is still a draft. The areas of intervention included in the Concept for digitalisation of the business, export orientation and competitiveness are as follows: building a stable relationship between the industry and the science in the country and a fastened integration of Bulgaria into European and international programs and projects; technological renovation of the Bulgarian economy through the introducing of standards, creating appropriate infrastructure, establishment of specific mechanisms for the improvement and market penetration of technological innovations; creation of human, scientific, organizational and institutional capacity for the development of Industry 4.0 in Bulgaria.

\section{FUTURE RESEARCH DIRECTIONS}

The transformation of the Bulgarian digital economy would increase its competitiveness and would place it at a leading position in the region. Due to these and many other reasons, discussed in this paper, it is important for these matters to be analyzed from a scientific point of view. There is not enough research on the topic in Bulgaria and this was the reason why the authors decided to focus on it in this paper. Future research on the matter should be directed at qualitative and quanti- 
tative measures implemented in assessing the state and potential of the digital economy in Bulgaria, similar to the ones analysed in the paper. Moreover, different possibilities for institutional and private initiatives and policies should also be discussed and further developed. Thus, providing a favourable environment in which all types of digital businesses in Bulgaria would thrive.

This paper contributes for the clearer formulation and understanding of the matters related to globalization as a whole, but also for tracking its impact on the state of digital companies in Bulgaria. Similar research can be applied and further developed for each and every European country and more.

\section{CONCLUSION}

Globalization has made it possible for business enterprises to conduct business operations that extend beyond their areas of establishment It has become increasingly easy for businesses of all types to participate in the world market because of IT, which virtually any business can access. Improved access to information by business enterprises supposes the opportunities to reach a greater consumer base. This is necessary even more due to the globalization of human capital, which is characterized by the easy migration of skills between countries. Because of the opportunities offered by information and communication technologies, the vision of perfect competition is also becoming a reality, which was not possible until recently. Competition is fostered by the increasing size of the market opened up through globalization.

Bulgaria's digital economy has also been greatly influence by the processes of globalization and the data analysed in this paper shows the great potential of the field, but also some challenges that it is facing. The implications of the research can be differentiated as follows: despite some impressive successes, the small digital companies are facing numerous challenges; there are some problems related to the dynamic of their ecosystem, the localization and solution of which are of great importance; the creation of future state policies specifically aimed at supporting and facilitation of the work of small and medium digital companies and start-ups is of great importance for their future, etc. When it comes to education necessary for this field, it is important that programs both at school and at universities are directed more at digitalisation studies and practices and less at old-fashioned disciplines and theories.

\section{REFERENCES}

European Commission. (2019). Digital Economy and Society Index (DESI) 2019 Country Report, Bulgaria. retrieved from https://ec.europa.eu/digital-single-market/en/scoreboard/ bulgaria

IMD World Competitiveness Center. (2019). IMD World Digital Competitiveness Ranking 2019, retrieved from https:/www.imd.org/wcc/world-competitiveness-center-rankings/ world-digital-competitiveness-rankings-2019/

McKinsey \& Company (2019). The Rise of Digital Challenges. How digitalization can become the new growth engine for Bulgaria and Central Eastern Europe (CEE), retrieved from https://digitalchallengers.mckinsey.com/files/McKinsey_Digital\%20Challengers_Perspective_on_Bulgaria_online.pdf

United Nations (2019). Digital Economy Report. Value Creation and Capture: Implications for Developing Countries. United Nations Conference on Trade and Development. Geneva, retrieved from https://unctad.org/en/PublicationsLibrary/der2019_overview_en.pdf 